Brazilian Journal

of Chemical

ISSN 0104-6632

Engineering

Printed in Brazil

www.scielo.br/bjce

Vol. 34, No. 04, pp. 1023 - 1034, October - December, 2017

$($ (c) $)$ EY

dx.doi.org/10.1590/0104-6632.20170344s20150660

\title{
AN ENTIRELY RENEWABLE BIOFUEL PRODUCTION FROM USED PALM OIL WITH SUPERCRITICAL ETHANOL AT LOW MOLAR RATIO
}

\author{
W. Sakdasri ${ }^{1}$, R. Sawangkeaw ${ }^{2}$ and S. Ngamprasertsith ${ }^{1,3^{*}}$ \\ ${ }^{1}$ Fuels Research Center, Department of Chemical Technology, Faculty of Science, Chulalongkorn University, Bangkok 10330, Thailand \\ ${ }^{2}$ The Institute of Biotechnology and Genetic Engineering, Chulalongkorn University, Institute Bldg. 3, 254 Phayathai Rd., \\ Pathumwan, Bangkok 10330, Thailand \\ ${ }^{3}$ Center of Excellence on Petrochemical and Materials Technology, Chulalongkorn University, 254 Phayathai Road, Pathumwan, \\ Bangkok 10330, Thailand \\ *Corresponding author: E-mail somkiat.n@chula.ac.th
}

(Submitted: October 19, 2015; Revised: April 25, 2016; Accepted: May 21, 2016)

\begin{abstract}
The biofuel production from used palm oil (UPO) using supercritical ethanol (SCE) at low molar ratio was investigated in order to produce an entirely renewable fuel. The effects of the reaction time and ethanol to oil molar ratio were considered from 0.5 to $10 \mathrm{~min}$ and $6: 1$ to $18: 1$, respectively. The optimal parameters were $10 \mathrm{~min}$ and a $12: 1$ molar ratio, representing a remarkable reduction from 42:1 for the conventional SCE process. Because of the high operating temperature, the triglycerides conversion rate reached $99 \%$, and the glycerides content met the international specification for biodiesel. However, an ester content of $70 \%$ was obtained at optimal conditions. The side reaction between glycerol and ethanol demonstrated a positive effect in increasing fuel yield by $8.15 \%$. The product can be considered an alternative biofuel instead of biodiesel.
\end{abstract}

Keywords: biofuel, supercritical ethanol,vegetable oil, used palm oil, low molar ratio

\section{INTRODUCTION}

The depletion of non-renewable petrochemical resources combined with concerns over global warming has focused the world's attention on the search for alternative sources of renewable energy. Biofuels synthesized from lipid-based biomass, especially biodiesel, offer a promising alternative substitute for petroleum-based fuels.

Biodiesel has potential utility as a sustainable, renewable fuel for transportation without requiring engine modification (Carraretto et al., 2004). In addition, biodiesel is an environment-friendly energy source, producing less air pollution compared with fossil fuels and trace emission of sulfur oxides. It also contributes to climate change mitigation by reducing net $\mathrm{CO}_{2}$ emissions from the transportation sector (Cetinkaya et al., 2005).In general, biodiesel is synthesized through the transesterification of vegetable oils with a short-chain alcohol. The commercial biodiesel production facilities mostly employ methanol (derived from fossil sources) as the reacting alcohol

\footnotetext{
* To whom correspondence should be addressed
} 
because of its low cost and favorable chemical and physical properties (Ma and Hanna, 1999). In contrast, ethanol is a renewable source; because it can be produced from biomass by fermentation and has similar chemical and physical properties, it has been proposed as a reacting alcohol in place of methanol (Rodrigues et al., 2009). Therefore, using ethanol provides a $100 \%$ renewable basis for biodiesel production feedstocks.

Used cooking oil is one interesting feedstock, with costs typically two or three times lower than that of virgin vegetable oil (Math et al., 2010). It has been reported that 0.7 to 1 and 0.2 million tons of used cooking oilis annually produced in European countries and the United Kingdom, respectively (Hamze et al., 2015). China and Japan generates about 4.5 and 0.6 million tons of used cooking oil per year, respectively (Diya'uddeen et al., 2012; Balat and Balat, 2010).This suggests the ready availability of used cooking oil to meet the future demand for biodiesel production. However, because of its high content of free fatty acid (FFA) and water resulting from the frying process, the conventional catalytic process, especially an alkali-catalytic process, is unsuitable for the conversion of used cooking oil as a feedstock because the alkaline catalysts react with FFA to form soaps, significantly reducing the biodiesel yield. The supercritical alcohol (SCA) process is an alternative route to resolve those problems without using catalysts. It has been reported that the presence of water and FFA in the feedstock, up to 36 and $30 \mathrm{wt} . \%$, respectively, does not affect the progress of transesterification in SCA (Tan et al., 2010; Kusdiana and Saka, 2004; Silva and Oliveira, 2014). These FFA can be esterified and converted into biodiesel. Hence, the SCA process carries the additional advantage that it can utilize low-quality feedstocks such as used cooking oil and crude palm oils as a source of triglyceride without encountering saponification problems.

In our previous study, a laboratory batch reactor was used in successful biofuel production from refined palm oil (RPO) using the SCA process at $400^{\circ} \mathrm{C}$ and $15 \mathrm{MPa}$ (Sawangkeaw et al., 2011). This novel process was employed to resolve the problem of the high alcohol to oil molar ratio ( $>40: 1)$ in the SCA process, which generated an environmental impact from the large energy input of preheating and recovering the alcohol (Kiwjaroun et al., 2009). The alcohol to oil molar ratio can be reduced to 12:1 and 18:1 for the supercritical methanol (SCM) and supercritical ethanol (SCE) processes at $400^{\circ} \mathrm{C}$ and $15 \mathrm{MPa}$, respectively. As proposed in some studies (Marulanda et al., 2010; Marulanda et al., 2009), the increase of the operating temperature to $350{ }^{\circ} \mathrm{C}-400{ }^{\circ} \mathrm{C}$ dramatically reduced the molar ratios from $40: 1-42: 1$ to $6: 1-12: 1$ at moderate pressures of 10.0-15.0 MPa. Moreover, this process also resulted in important advantages, most importantly an increase of approximately $5 \%-10 \%$ in fuel yields and a reduction in the alcohol to oil molar ratio. In addition, the lower proportion of alcohol required is reflected in a lower energy requirement for alcohol preheating, pumping, and recovery compared with conventional SCA processes with a 42:1 alcohol to oil molar ratio (Sawangkeaw et al., 2012). Thus, this work selected reaction conditions of $400{ }^{\circ} \mathrm{C}$ and $15 \mathrm{MPa}$ to reduce the employment of alcohol for biofuel production from used palm oil (UPO) with SCE. The effects of the reaction time and ethanol to oil molar ratioswere investigated to explore the utility of the SCE process and its potential for scale-up to a continuous process.

\section{EXPERIMENTAL}

\section{Materials}

The UPO in this study was collected from a local restaurant near Chulalongkorn University, Bangkok, Thailand. The RPO was supplied from Morakot Industries Co., Ltd. Analytical grade ethanol and glycerol supplied by Fisher.To measure the ethyl ester content in the biofuel products, analytical grade methyl heptadecanoate (99.5\%) was used as an internal standard, and $n$-heptane (99.5\%) was used as an analytical solvent, supplied by Fluka and Fisher, respectively.

\section{Experimental set-up and procedure}

The reactions of UPO and glycerol with SCE were investigated in a constant-volume batch reactor. The batch reactor was constructed from stainless steel tubing (closed at both ends) of $9.52-\mathrm{mm}$ outside diameter, $1.24-\mathrm{mm}$ thickness, and $110-\mathrm{mm}$ length with a volume of $4-\mathrm{mL}$. The reactor vessel was heated in a fluidized sand bath using a k-type thermocouple and a proportional-integral-derivative controller (PID controller) to monitor and control the temperature, respectively.

The reactor was then charged with UPO and ethanol in amounts calculated using the Redlich-Kwong equation of state to obtain the desired pressure of $15 \mathrm{MPa}$, including the amount of ethanol and glycerol at the molar ratio of $9: 1$. Because the total volume of reactants was commonly higher than 3-mL, the effect of the initial air in the 4-mL reactor, which could cause oxidation at $400{ }^{\circ} \mathrm{C}$, could be neglected. The reaction times ranged from $0.5-10 \mathrm{~min}$. The testing reactor was immersed into a fluidized sand bath at the desired temperature and shaken manually from time to time to ensure uniform mixing. Note that the heating rate of this reactor is $30^{\circ} \mathrm{C} / \mathrm{s}$ as reported in our previous work (Sawangkeaw et al., 2010). At the end of the reaction, the reactor was then quenched in a water bath to stop the reaction. Excess ethanol was removed by rotary evaporation at $50{ }^{\circ} \mathrm{C}$ and $15 \mathrm{mbars}(1.5 \mathrm{kPa})$ for 30 min. The biofuel products were collected for analysis by gas chromatography $(\mathrm{GC})$, from which the triglyceride conversion level $\left(\mathrm{X}_{\mathrm{TG}}\right)$ was obtained. 


\section{Feed and product analysis}

The UPO was filtered to remove food residues before examining its properties. The physical properties of the UPO sample were analyzed using standard testing methods, including the water content (EN ISO 12937), iodine value (ASTM D5554), and acid value (ASTM D664). In determining the distribution of fatty acid, the American Oil Chemists' Society standard (AOCS Ce297) was applied to prepare an ethyl ester (FAEE) sample. The ethyl ester content in the FAEE sample was measured based on the peak area obtained from GC, Shimadzu GC14B, equipped with a capillary column (DB-WAX) and a flame ionization detector. The temperatures of the injector and detector were set at $250{ }^{\circ} \mathrm{C}$. The column temperature was set at $180^{\circ} \mathrm{C}$, with a holding time of $8 \mathrm{~min}$, and then increased to $200{ }^{\circ} \mathrm{C}$ at a heating rate of $10^{\circ} \mathrm{C} / \mathrm{min}$.

The biofuel products were analyzed for their ester content and triglyceride conversion using a GC, Varian Technology Model CP3800, equipped with a capillary column (Rtx ${ }^{\circledR}-65 \mathrm{TG}, 30-\mathrm{m}$ length, 0.250-mm I.D.) and a flame ionization detector. The temperatures of the injector and detector were set at $360{ }^{\circ} \mathrm{C}$. The column temperature was set at $150^{\circ} \mathrm{C}$, with a holding time of $3 \mathrm{~min}$, and then increased to $370{ }^{\circ} \mathrm{C}$ at a heating rate of $15{ }^{\circ} \mathrm{C} / \mathrm{min}$. The $\mathrm{GC}$ chromatogram of an incomplete conversion sample is shown in Figure 1. The determination of \%FAEEs of each biofuel sample followed the European standard method EN 14103:2003 and employed methyl heptadecanoate as the internal standard. To quantify unreacted triglyceride in synthesized biofuel, 5-level solutions of palm oil in n-heptane were used in the external calibration. In addition, the triglyceride conversion level $\left(\% \mathrm{X}_{\mathrm{TG}}\right)$ was calculated using Equation 1.

$$
X_{T G}(\%)=100 \times\left(1-\frac{\mathrm{TG}_{\text {Unreact }}}{\mathrm{TG}_{\text {Initial }}}\right)
$$

where $X_{T G}$ is the \% triglyceride conversion level, $T G_{\text {Unreact }}$ is the unreacted triglyceride level $(\mathrm{g} / \mathrm{L})$ in the resultant biofuel (measured by GC), and $T G_{\text {Inital }}$ isthe initial triglyceride level (g/L) in the UPO reactant (also measured by GC).

The compounds in the biofuel and the ethanol-glycerol samples were identified by gas chromatography-mass spectroscopy (GC-MS), Shimadzu, model GCMSQP2010, equipped with a capillary column (Agilent J\&W DB-5 ms, 20-m length $\times 0.1$-mm o.d. $\times 0.1-\mu \mathrm{m}$ film thickness). For the biofuel samples, the column was started at $60{ }^{\circ} \mathrm{C}$ (held for $2 \mathrm{~min}$ ), ramped to $270{ }^{\circ} \mathrm{C}$ at $20^{\circ} \mathrm{C} / \mathrm{min}$, and then held at the final temperature at $270^{\circ} \mathrm{C}$ for $2 \mathrm{~min}$. The temperature program for the ethanol-glycerol reaction products started at $60^{\circ} \mathrm{C}$ (held for $2 \mathrm{~min}$ ), ramped to 115 ${ }^{\circ} \mathrm{C}$ (held for $1 \mathrm{~min}$ ) at $5{ }^{\circ} \mathrm{C} / \mathrm{min}$, and then ramped to $220^{\circ} \mathrm{C}$ (held for $20 \mathrm{~min}$ ) at $10^{\circ} \mathrm{C} / \mathrm{min}$.

The distillation (volatility) characteristics of the biofuel samples were analyzed by distillation gas chromatograph

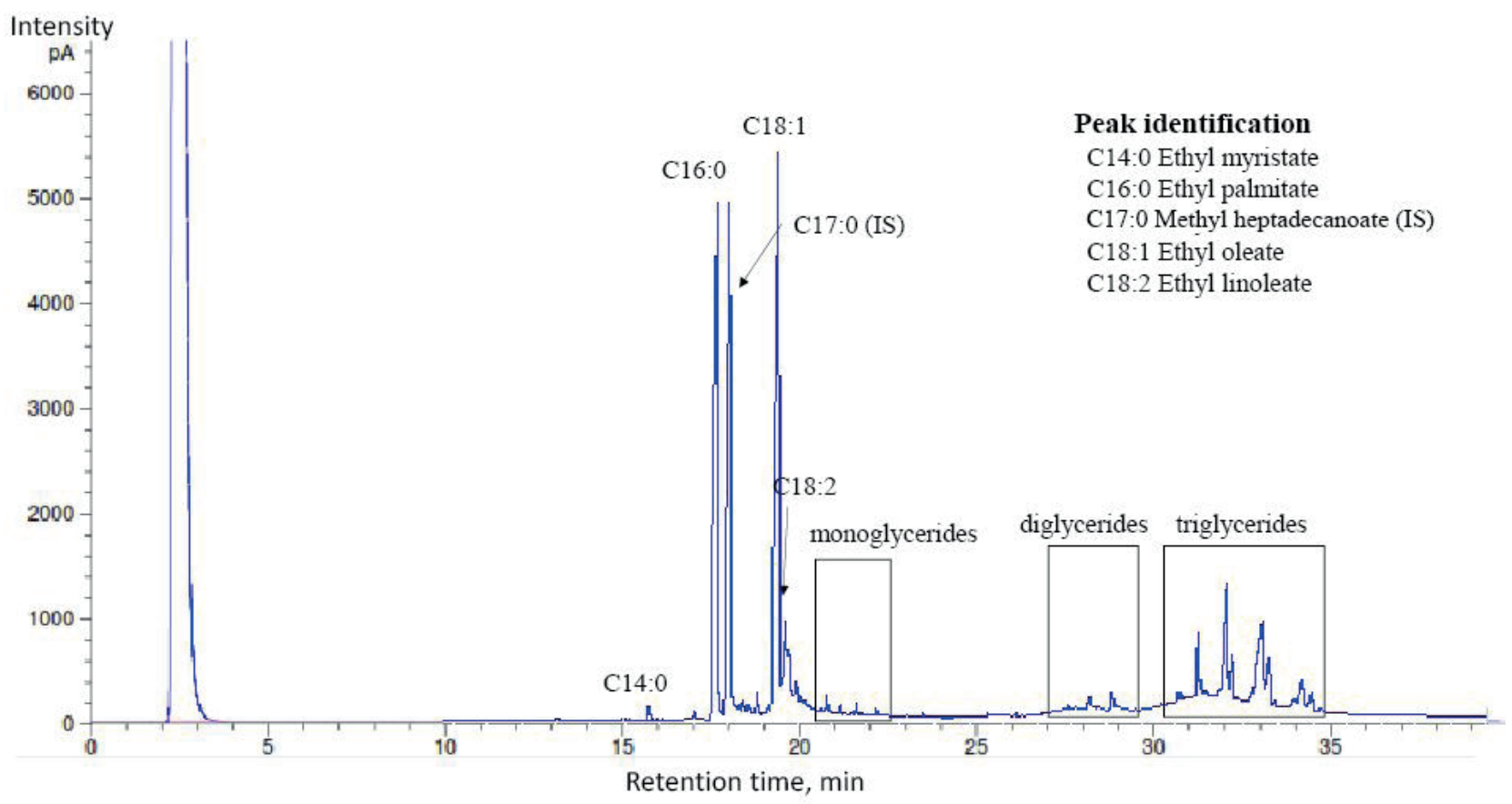

Figure 1. GC chromatogram of biofuel sample synthesized from UPO in SCE at $400{ }^{\circ} \mathrm{C} . \mathrm{C} 17: 0$ (IS) is an internal standard (methyl heptadecanoate). 
(DGC), followed ASTM D2887-14, Agilent Technology Model $6890 \mathrm{~N}$, equipped with a capillary column (5-m length $\times 0.53-\mathrm{mm}$ o.d. $\times 0.09-\mu \mathrm{m}$ film thickness, SIMDIS HT750, Analytical Controls) and a flame ionization detector. The temperature program was held at $30^{\circ} \mathrm{C}$ and was then increased to $320^{\circ} \mathrm{C}$ at $10^{\circ} \mathrm{C} / \mathrm{min}$. The holding time at the final temperature $\left(320^{\circ} \mathrm{C}\right)$ was $20 \mathrm{~min}$. The boiling ranges of biofuel sampleprecisely determined based on the calibration curve between boiling point of normal aliphatic hydrocarbon standard and retention time. For example, the boiling ranges of gasoline $(\mathrm{C} 4-\mathrm{C} 12)$ is $100-180^{\circ} \mathrm{C}$ which represent as retention time of $0-5 \mathrm{~min}$, kerosene $(\mathrm{C} 12-\mathrm{C} 16)$ is $180-250^{\circ} \mathrm{C}$ which represent as retention time of 5-10 min and so on. The \%mass recovery was calculated from summation of peak area between those represented retention times.

\section{RESULTS AND DISCUSSION}

\section{Properties of RPO and UPO}

A comparison of the physical and chemical properties of the RPO and UPO samples is presented in Table 1. The UPO differs in physical properties from RPO, especially in the acid value, because of the higher level of FFA produced from the hydrolysis reaction during the cooking process (Bastida and Sanchez-Muniz, 2002). The acid value is directly related to the levels of FFA in the samples that can be determined by calculation following ASTM D664. Therefore, the \%FFA can be derived as 4.50 wt. \% from the acid value of $9.62 \mathrm{mg} \mathrm{KOH} / \mathrm{g}$. According to alkali- catalyzed biodiesel production, a feedstock requires FFA levels below $0.50 \mathrm{wt} . \%$. Thus, it is clear that a pre-treatment process would be required to use UPO as a feedstock because the FFA can react with the alkali-catalyst to form soaps, which reduces ester yield in the product (Encinar et al., 2011). However, the FFA do not significantly affect the supercritical transesterification with methanol and ethanol (Kusdiana and Saka, 2004; Tan et al., 2010; Vieitez et al., 2012). Under supercritical conditions, the FFA can be esterified to produce fatty acid alkyl ester, increasing the ester yield and process efficiency (Sawangkeaw et al., 2011). Furthermore, the amount of FFA in the feedstocks, approximately $10 \%$, shows the catalytic activity, which results in higher conversions in SCM and SCE processes (Minami and Saka, 2006; Vieitez et al., 2012).The fast reaction rates of the simultaneous transesterification and esterification reactions were also reported in the biodiesel production from Jatropha curcas L. oil (>10\% FFA) in SCE at the lowered operating conditions (Silva et al., 2014).

The water content in the feedstocks could affect the conversion in the transesterification reaction using the conventional acid-catalyzed method, as reported in a previous study (Kusdiana and Saka, 2004). However, the water contents in RPO and UPO are very low, as indicated in Table 1; thus, the effect of water is negligible in this study.

The UPO mainly comprises $35.33 \%$ palmitic acid, $38.50 \%$ oleic acid, and $11.51 \%$ linoleic acid, which can be transesterified to a main product, i.e., fatty acid ethyl esters (FAEEs) in biofuel. Fatty acid ester derived from

Table 1. The physical and chemical properties of RPO and UPO samples.

\begin{tabular}{|c|c|c|c|c|}
\hline \multirow[b]{2}{*}{ Fatty acid composition } & \multirow[b]{2}{*}{ Carbon number } & \multirow[b]{2}{*}{ Degree of unsaturation } & \multicolumn{2}{|c|}{ Samples } \\
\hline & & & $\begin{array}{c}\text { RPO }^{a} \\
\text { (wt. \%) }\end{array}$ & $\begin{array}{c}\text { UPO } \\
\text { (wt. \%) }\end{array}$ \\
\hline Lauric acid & 12 & 0 & $0.45 \pm 0.1$ & $5.72 \pm 2.5$ \\
\hline Myristic acid & 14 & 0 & $1.10 \pm 0.2$ & $4.41 \pm 1.6$ \\
\hline Palmitic acid & 16 & 0 & $46.14 \pm 2.4$ & $35.33 \pm 3.6$ \\
\hline Stearic acid & 18 & 0 & $4.43 \pm 0.1$ & $4.42 \pm 0.9$ \\
\hline Total saturated fatty acids & & & $52.12 \pm 2.8$ & $49.88 \pm 8.6$ \\
\hline Palmitoleic acid & 16 & 1 & $\mathrm{~N} / \mathrm{D}$ & $\mathrm{N} / \mathrm{D}$ \\
\hline Oleic acid & 18 & 1 & $37.12 \pm 4.6$ & $39.96 \pm 1.5$ \\
\hline Linoleic acid & 18 & 2 & $11.10 \pm 1.0$ & $11.51 \pm 1.4$ \\
\hline Linolenic acid & 18 & 3 & $0.21 \pm 0.1$ & $0.34 \pm 0.2$ \\
\hline Total unsaturated fatty acids & & & $48.43 \pm 5.7$ & $51.81 \pm 3.1$ \\
\hline Acid value (mg KOH/g) & & & $0.21 \pm 0.05$ & $9.62 \pm 1.5$ \\
\hline Water content $(\mathrm{g} / 100 \mathrm{~g})$ & & & $0.04 \pm 0.05$ & $0.14 \pm 0.04$ \\
\hline Iodine value $(g / 100 g)$ & & & $53.60 \pm 5$ & $68.47 \pm 5$ \\
\hline Molecular weight & & & 840 & 858 \\
\hline
\end{tabular}

${ }^{a}$ Obtained from Morakot Industries Co., Ltd.; N/D is not detected. 
oleic acid has been proposed as a suitable candidate for improving fuel properties because of its high oxidation stability compared with other fatty acids containing two or three double bonds (Knothe, 2008). Studies of ethyl oleate, especifically on its fuel properties, are not available; but the same results as for methyl oleate would be expected. In addition, UPO contained higher levels of lauric acid (C12:0) and myristic acid (C14:0) than that RPO, most likely resulting from the decomposition of high-molecularweight fatty acids, especially polyunsaturated fatty acids. As reposted in the literature, the lauric acid and myristic acid contents in palm oil are naturally present in the range of $0.1-0.4$ wt.\% and $0.9-1.4$ wt.\%, respectively (Lee and Ofori-Boateng, 2013).

\section{Effect of reaction times}

The effect of reaction time was investigated from 0.5 to $10 \mathrm{~min}$, and the variation of the levels of FAEEs with reaction time at an ethanol to oil molar ratio of 18:1 is shown in Figure 2. The total FAEEs content increases steadily with reaction times up to $8 \mathrm{~min}$ and then tends to decrease because of the decrease of ethyl palmitate (C16:0), ethyl oleate (C18:1), and ethyl linoleate (C18:2). Ethyl palmitate (C16:0) and ethyl oleate (C18:1) were observed as the main components, which corresponded to the primary composition in Table 1 . This observation indicates that the initially formed FAEEs can degrade with excessive reaction times at high temperature, as previously reported in the literature (Sawangkeaw et al., 2011; Imahara et al., 2008). In addition, it is evident that ethyl linoleate (C18:2) is more rapidly degraded, with a decline starting at $5 \mathrm{~min}$ of reaction time. As a polyunsaturated fatty acid containing two double bonds, ethyl linoleate (C18:2) is increasingly unstable at higher temperatures compared with the monounsaturated and saturated ones. A similar behavior was likewiseobserved in the biodiesel production of soybean with SCE (Vieitez et al., 2011), ethyl linoleate (C18:2) and ethyl linolenate (C18:3) drastically reduce relative to ethyl palmitate $(\mathrm{C} 16: 0)$ at the highest temperature of $370{ }^{\circ} \mathrm{C}$. The thermal cracking products are comprised of small compounds, i.e., alkane hydrocarbons in the range of C9-C10 as shown in Table 4 (see Section Reaction between glycerol and supercritical ethanol). Although the decomposition of FAEEs is not desirable in biodiesel production, some products, such as small hydrocarbons (C7-C14), could improve cold flow properties, density and viscosity, which was suggested for an additive for biofuel (Sawangkeaw et al., 2011).

As mentioned earlier, the transesterification and/ or esterification reactions are the main reactions in SCE at $400{ }^{\circ} \mathrm{C}$. Therefore, the effect of reaction time on the triglyceride conversion $\left(\% \mathrm{X}_{\mathrm{TG}}\right)$ was also investigated to establish the optimal reaction time for the process. In addition, due to the decomposition of FAEEs observed at this reaction temperature $\left(400{ }^{\circ} \mathrm{C}\right)$, the FAEEs yield could not be maximized to meet the $96.5 \%$ of the biodiesel standard value. The conversion of triglyceride was observed to minimize the glycerides content as specified by The European Standard (EN 14214) (see Section Effect of molar ratio). The data indicate that $\% \mathrm{X}_{\mathrm{TG}}$ increased rapidly at the beginning of the reaction, reaching a plateau of approximately $99 \%$ at a reaction time of $10 \mathrm{~min}$ for

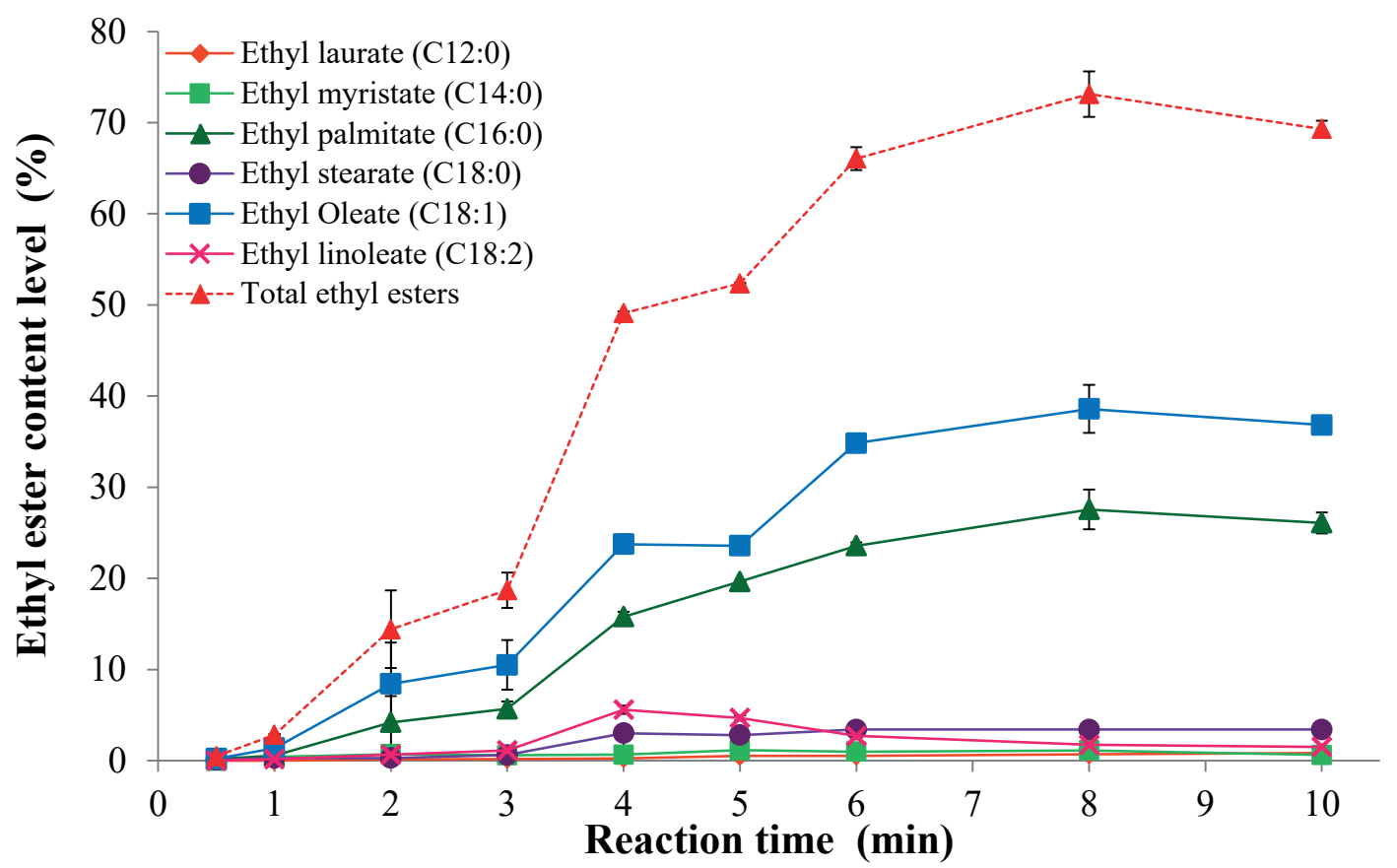

Figure 2. Ester contents of biofuel samples from UPO as a function of reaction time (reaction conditions: $400{ }^{\circ} \mathrm{C}, 15 \mathrm{MPa}$ at $18: 1$ of ethanol to oil molar ratio). 


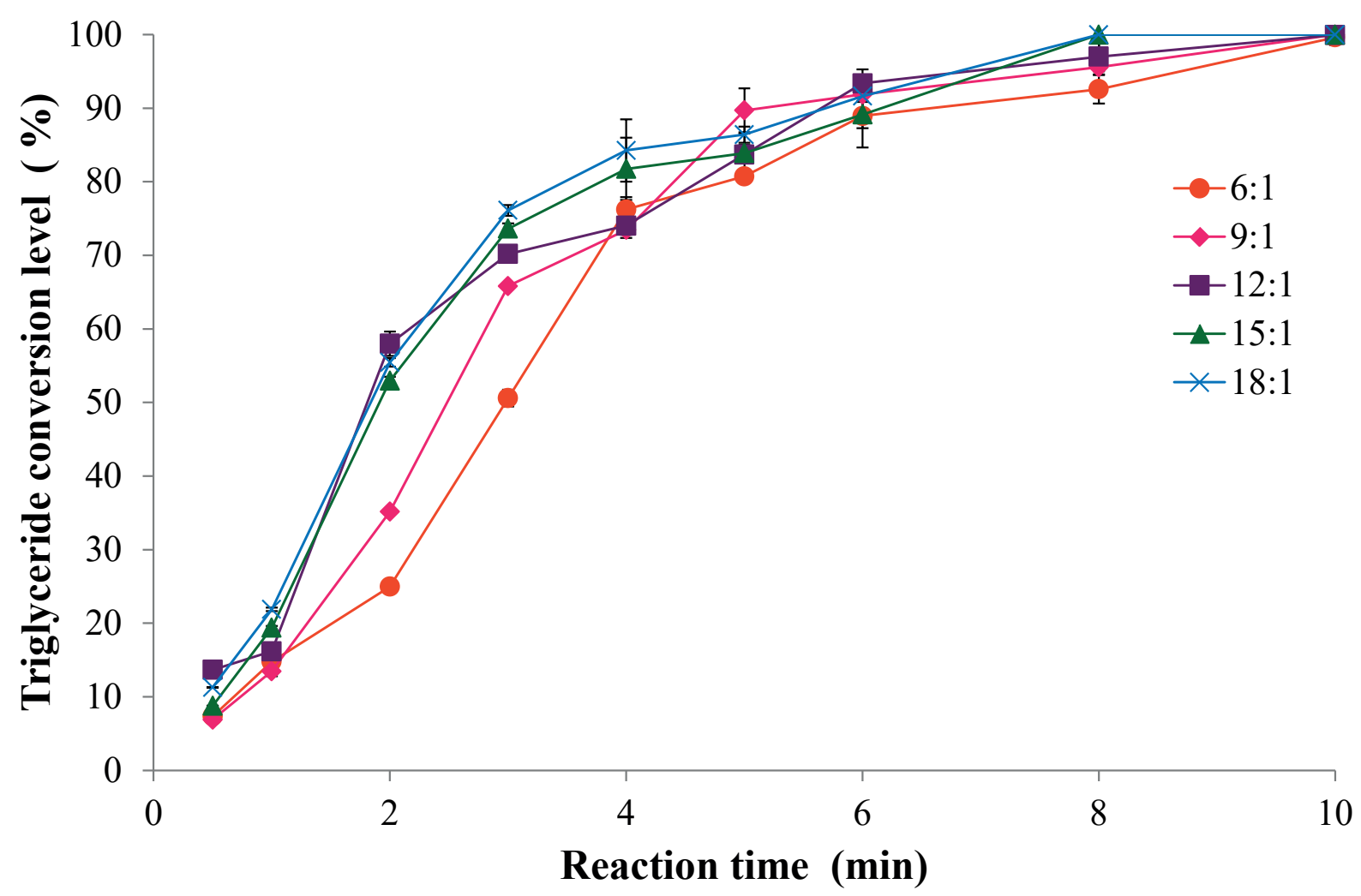

Figure 3. Triglyceride conversion level $\left(\% \mathrm{X}_{\mathrm{TG}}\right)$ of biofuel samples from UPO as a function of reaction time at $400{ }^{\circ} \mathrm{C}$ and $15 \mathrm{MPa}$.

all the ethanol to oil molar ratios (Figure 3). With the triglyceride conversion close to $100 \%$, it can be concluded that a reaction time of $10 \mathrm{~min}$ is optimal to ensure the complete transesterification reaction for biofuel production with SCE at $400{ }^{\circ} \mathrm{C}$.

\section{Effect of molar ratio}

The molar ratio of alcohol to oil has been reported to be one of the most important variables affecting the yield of fatty acid alkyl ester (He et al., 2007). In this study, an ethanol to oil molar ratio 2-6 fold higher than the stoichiometric requirement $(3: 1)$ was considered because ethanol is consumed by multiple reactions such as the transesterification of triglycerides, esterification of FFA, and etherification reaction of glycerol, as observed in the mass balance analysis (see Section Mass balance). Figure 4 shows the change of the total FAEEs and triglyceride conversion with variation of the ethanol to oil molar ratio at a fixed reaction time of $10 \mathrm{~min}$. The FAEEs content was observed to increase with increasing ethanol to oil molar ratio, and is consistent with the literature (Song et al., 2008; Varma and Madras, 2007). This finding is explained by the lowering of the critical point of the UPO-ethanol mixture with increasing alcohol content (Anitescu et al., 2008; Sakdasri et al., 2015). However, the FAEEs yield was observed in the highest values only of $71.76 \%$ at the molar ratio of $12: 1$. This is not only due to the thermal decomposition, but also the contaminant of several compounds in UPO that cannot be converted to ethyl ester. As reported in the literature (Gonzalez et al., 2013; Abdala et al., 2014), the maximum ester content reachable from the waste feedstock can be determined by the novel parameter, called convertibility. The convertibility of soybean fried oil and used frying oil was found to be $92.1 \%$ and $93.1 \%$, respectively.

The presence of mono-, di-, and triglycerides in the biofuel is a key indicator of the biodiesel quality (Dias et al., 2014); the levels of remaining glycerides in the samples produced in this study are presented in Figure 5. The EN 14214 requires levels of mono-, di-, and triglycerides below $0.80,0.20$, and 0.20 mass $\%$, respectively. Thus, the glyceride levels in biofuel samples produced using ethanol to oil molar ratios from 9:1 were within the requirements of this specification.

Table 2 shows the distillation (volatility) characteristic of biofuel samples obtained from varied ethanol to oil molar ratios. Because a small amount of sample is available, this characteristic was analyzed using the simulated distillation gas chromatograph (ASTM D2887-14). This characteristic has an important effect on the safety and performance of the fuels and is directly related to the boiling point of the fuel composition. The results indicate that all of the biofuel samples had lower initial boiling points (IBPs) than the standard biodiesel $\left(120^{\circ} \mathrm{C}\right)$ because of the decomposition of FAEEs into the low-molecular-weight compounds, as 
Table 2. Distillation characteristics of biofuel samples from UPO as a function of ethanol to oil molar ratio (reaction conditions: $400{ }^{\circ} \mathrm{C}$ at 15 $\mathrm{MPa}$, and $10 \mathrm{~min}$ reaction time).

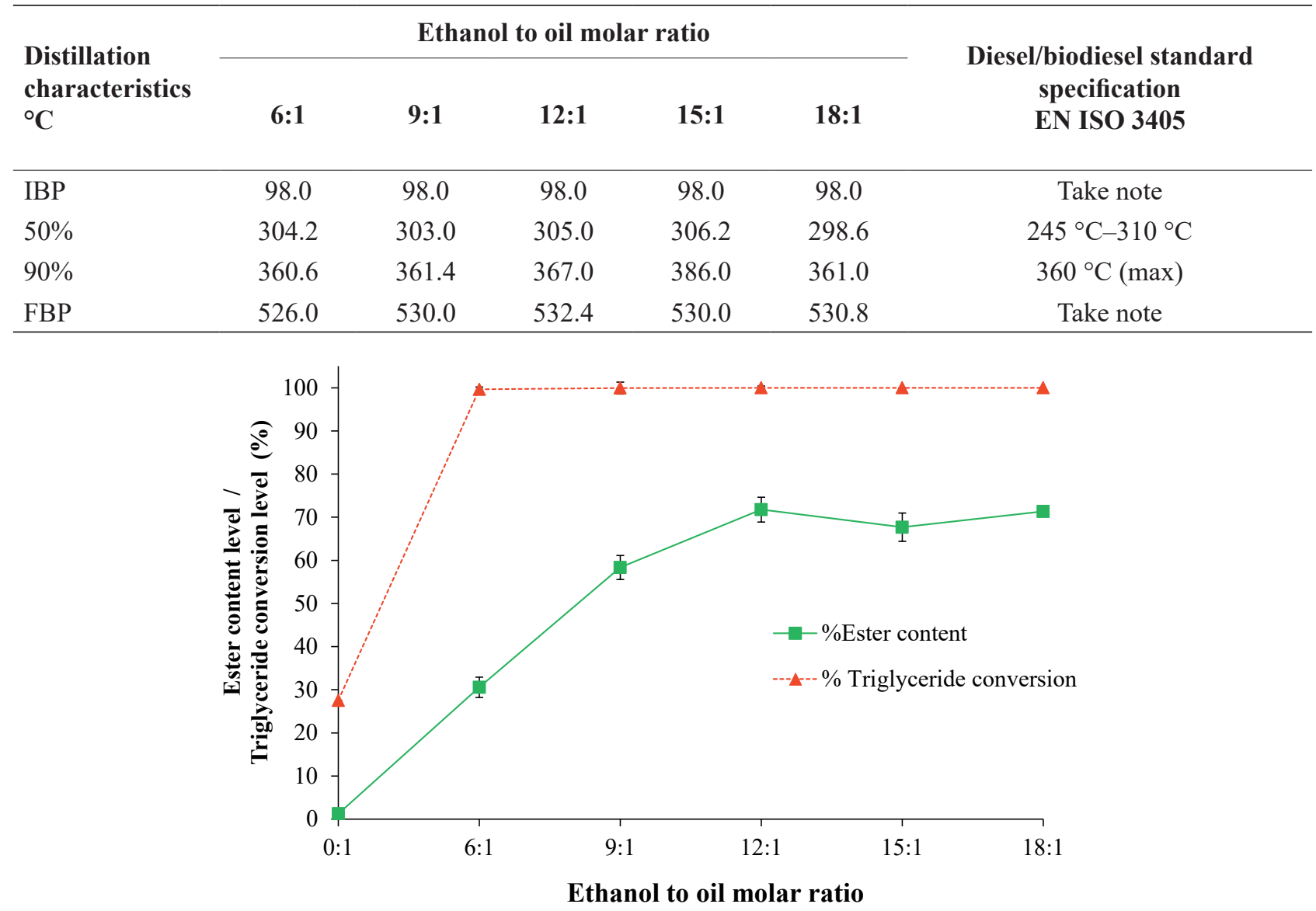

Figure 4. Ester content and triglyceride conversion, and glyceride levels of biofuel samples from UPO as a function of ethanol to oil molar ratio (reaction conditions: $400{ }^{\circ} \mathrm{C}$ at $15 \mathrm{MPa}$, and 10 min reaction time).

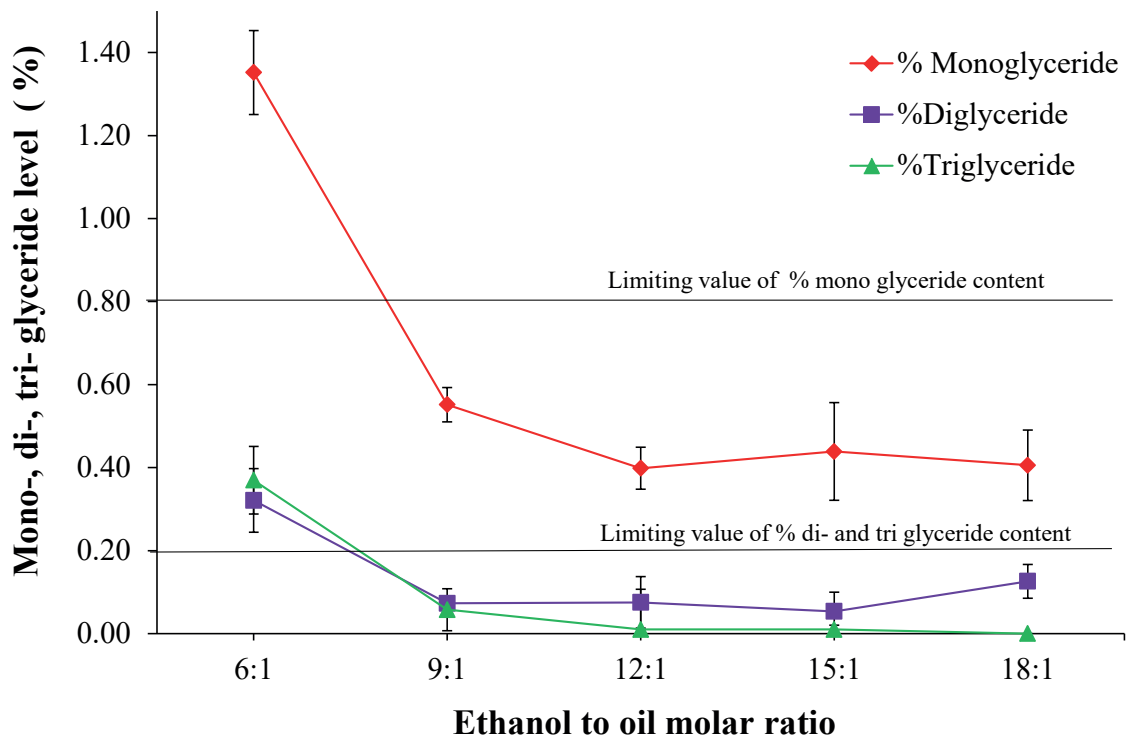

Figure 5. Glycerides levels in biofuel samples from UPO as a function of ethanol to oil molar ratio (reaction conditions: $400{ }^{\circ} \mathrm{C}$ at $15 \mathrm{MPa}$, and 10 min reaction time). 
proposed in previous studies (Sawangkeaw et al., 2011). Note that the low-molecular-weight could solve the cold start problem of biofuel. The temperatures corresponding to $50 \%$ distillation ranged from approximately $298.6^{\circ} \mathrm{C}$ to $306.2^{\circ} \mathrm{C}$. These values align within the temperature range specified by EN ISO $3405\left(245^{\circ} \mathrm{C}-310^{\circ} \mathrm{C}\right)$. However, the temperature of $90 \%$ distillation recovery $\left(360.6{ }^{\circ} \mathrm{C}-386.0\right.$ ${ }^{\circ} \mathrm{C}$ ) was observed to be slightly above the maximum limit of EN ISO 3405.

The effect of the ethanol to oil molar ratio on the boiling point distribution of the biofuel samples is illustrated in Figure 6. The biofuel samples obtained from 6:1 to $15: 1$ ethanol to oil molar ratios had diesel as the main fraction, approximately $70 \%$. The diesel fraction slightly decreased to $60 \%$ when the reaction was performed at an 18:1 ethanol to oil molar ratio because of the increasing light fractions (gasoline and kerosene). The light fractions correspond to the low molecular weight compounds, generated from the thermal decomposition of polyunsaturated fatty acid and etherification of glycerol. However, it has been reported that the gasoline and kerosene fractions considerably improve the cold flow properties and viscosity but decrease the flash point (Sawangkeaw et al., 2011). With the existence of the high amount of diesel fraction (up to $75 \%$ ), that resultant biofuel is very promising as diesel fuel. In addition, the percentage of the residual fraction decreased with an increasing ethanol to oil molar ratio and remained nearly constant at alcohol to oil molar ratios above 12:1. Therefore, it could be concluded that the ethanol to oil molar ratio of 12:1 is the optimal ratio to avoid surplus alcohol use in the SCE process.

\section{Mass balance}

As previously mentioned, this novel process can increase the fuel yield; thus, the mass balance should be consideredto compare the obtained experimental with theoreticalvalues. In this study, the mass balance of the overall theoretical reactions was calculated based on the simple reactions involved in the process, following Marulanda et al.(2010). The transesterification reaction of a stoichiometric mixture of triglyceride (TG) and ethanol produces FAEEs and glycerol, as shown in Equation 2.

$$
\mathrm{TG}+3 \mathrm{EtOH}=3 \text { FAEEs }+ \text { glycerol }
$$

With the addition of FFA in UPO feedstocks, esterification reactions of FFA with ethanol will also occur:

$$
\mathrm{FFA}+\mathrm{EtOH}=\mathrm{FAEE}+\mathrm{H}_{2} \mathrm{O}
$$

The complete mass balance of biofuel production under the optimal molar ratio (12:1) is shown in Figure 7. In accordance with the acid value of $9.62 \mathrm{mg} \mathrm{KOH} / \mathrm{g}$ oil, the FFA content is estimated to be 4.50 wt. $\%$, and the

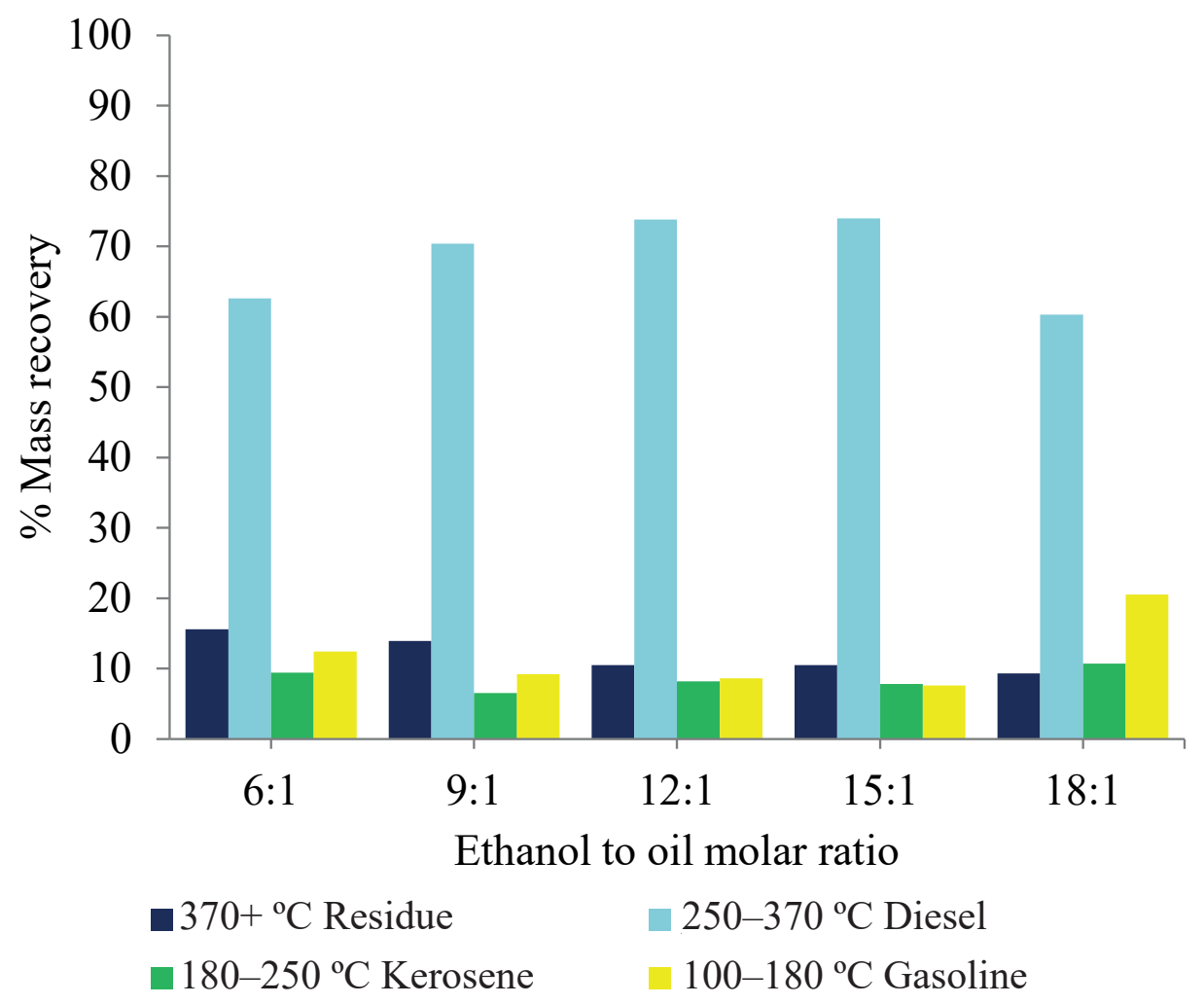

Figure 6. The boiling point distribution of biofuel samples from UPO as a function of the ethanol to oil molar ratio (reaction conditions: 400 ${ }^{\circ} \mathrm{C}$ at $15 \mathrm{MPa}$, and 10 min reaction time). 
triglyceride content is $95.50 \mathrm{wt} . \%$ on the basis of 100.00 $\mathrm{kg}$ UPO feedstock. It is evident that $100.00 \mathrm{~kg}$ of UPO will theoretically react with $16.14 \mathrm{~kg}$ of ethanol, which was divided into $15.38 \mathrm{~kg}$ and $0.76 \mathrm{~kg}$ for the consumption of the transesterification and esterification reactions, respectively. Therefore, the outlet products will be obtained after evaporation and separation processes, consisting of $48.42 \mathrm{~kg}$ of excess ethanol, $99.86 \mathrm{~kg}$ of FAEEs (fuel phase), and $16.28 \mathrm{~kg}$ of glycerol and water phase.

Table 3 presents the experimentally observed values in a 4-mL batch reactor, which were simplified to the basis of $100.00 \mathrm{~kg}$ UPO as feedstock, compared with the theoretically obtained value from Figure 7 . The fuel yield was increased by approximately $8.15 \%$, as indicated by the mass of the fuel phase $(108.15 \mathrm{~kg})$ divided by the mass of UPO $(100.00 \mathrm{~kg})$. However, the increased fuel yield from UPO was less compared with that obtained using RPO as the feedstock (Sawangkeaw et al., 2011). This finding was most likely because of the lower triglyceride content in UPO compared with RPO, as mentioned in the Section "Properties of RPO and UPO".

The observed weight of the glycerol phase $(2.32 \mathrm{~kg})$ was lower than the theoretical value $(16.28 \mathrm{~kg})$ because of the etherification of glycerol and ethanol at $400{ }^{\circ} \mathrm{C}$. The presence of the etherification reaction is indicated by the slightly higher weight of ethanol consumed in the experiment $(64.56-42.88=21.68 \mathrm{~kg})$ compared with the theoretical value $(16.14 \mathrm{~kg})$. The etherification products are identified in the Section "Reaction between glycerol and supercritical ethanol". It has been reported that the products of the etherification reaction are completely miscible with biofuel and even help to improve some of its properties (Marulanda et al., 2010).

A gas phase of approximately $11.21 \%$ was observed, as determined by the weight loss method; however, no further analysis of this phase was possible because of the small volume of gaseous products obtained from the 4-mL reactor. These gaseous products may include methane, ethane, and carbon dioxide, as reported for biofuel production from palm oil, as a product of high-temperature thermal cracking (Sawangkeaw et al., 2011).

\section{Reaction between glycerol and supercritical ethanol}

As mentioned above, the disappearance of ethanol and glycerol results from the etherification reaction. Thus, the ethanol-glycerol mixture was placed in a constant volume batch reactor at $400{ }^{\circ} \mathrm{C}$ and $15 \mathrm{MPa}$ with a reaction time of $10 \mathrm{~min}$ to confirm the occurrence of the etherification reaction. The ethanol to glycerol molar ratio was set at 9:1 because it is the molar ratio after $100 \%$ of the triglycerides conversion is achieved. Table 4 lists the products obtained from the ethanol-glycerol reaction and biofuel samples identified by GC-MS. The observation of 2-ethoxy-1,3-propanediol and 1,2,3-triethoxypropane in both samples confirmed that the etherification reaction occurred in the supercritical condition. Moreover, the 2-ethoxy-1,3-propanediol in the biofuel sample implied that the product from the ethanol-glycerol reactions can dissolve in the fuel phase and can increase the fuel yield by approximately $8.15 \%$. As proposed in the previous study, the reaction products of glycerol, mainly ether isomers of glycerol, could be directly used as part of the biofuel and improve some fuel properties (Marulanda et

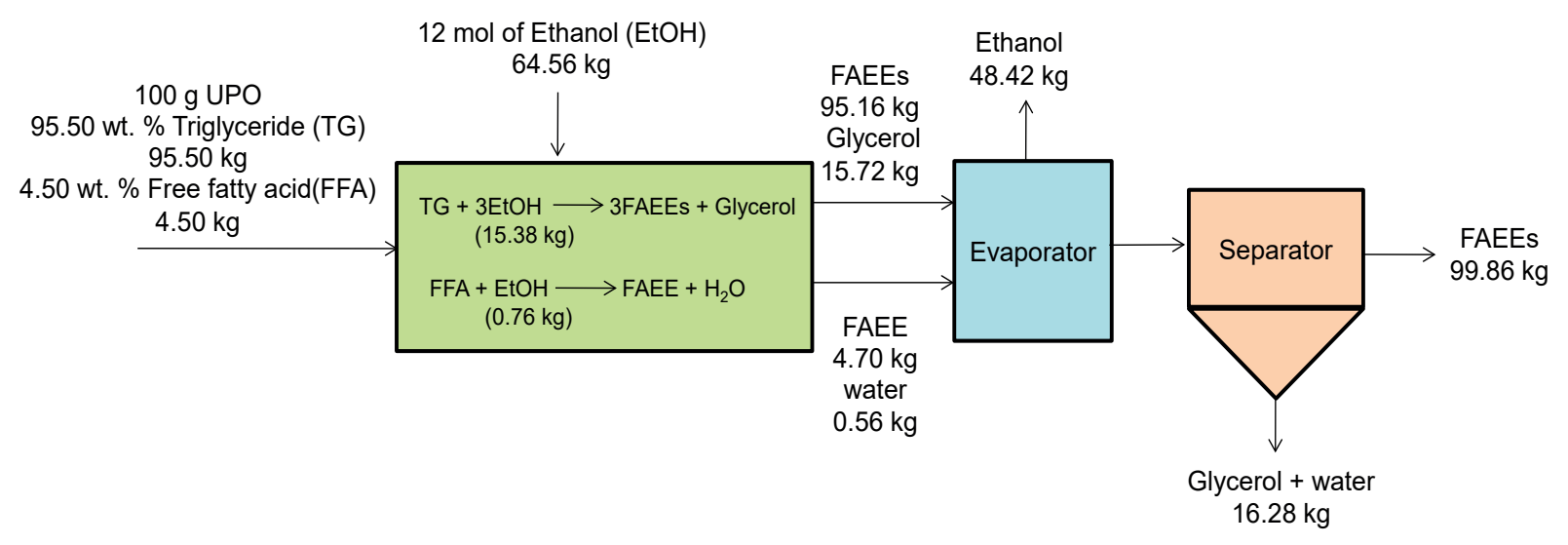

Figure 7. Flow sheet of the process with mass balance of biofuel production under the optimal molar ratio (12:1).

Table 3. Simplified mass balance of biofuel production from UPO with SCE at $400{ }^{\circ} \mathrm{C}, 12: 1$ ethanol to oil molar ratio, and $15 \mathrm{MPa}$ as observed in the experiment.

\begin{tabular}{lcccccc}
\hline & \multicolumn{2}{c}{ Feed $(\mathbf{k g})$} & \multicolumn{3}{c}{ Outlet $(\mathbf{k g})$} \\
\cline { 2 - 7 } Process & UPO & Ethanol & Fuel phase & Ethanol & $\begin{array}{c}\text { Glycerol + water } \\
\text { phase }\end{array}$ & Gas phase \\
\hline SCE & 100 & 64.56 & 108.15 & 42.88 & 2.32 & 11.21 \\
\hline
\end{tabular}


Table 4. Identified compounds in the product of the ethanol-glycerol reaction and product of biofuel based on GC-MS.

\begin{tabular}{|c|c|c|c|}
\hline Name & Formula & Structure & Fractional group \\
\hline 2-Ethoxy-1,3-propanediol ${ }^{\mathrm{a}, \mathrm{b}}$ & $\mathrm{C}_{5} \mathrm{H}_{12} \mathrm{O}_{3}$ & & Ether \\
\hline 1,2,3-Triethoxypropane ${ }^{a}$ & $\mathrm{C}_{9} \mathrm{H}_{20} \mathrm{O}_{3}$ & & Ether \\
\hline 2-Propoxybutane ${ }^{\mathrm{a}}$ & $\mathrm{C}_{7} \mathrm{H}_{16} \mathrm{O}$ & & Ether \\
\hline Glycerol $^{\mathrm{a}}$ & $\mathrm{C}_{3} \mathrm{H}_{8} \mathrm{O}_{3}$ & $\mathrm{OH}$ & Hydroxyl \\
\hline Nonane $^{\mathrm{b}}$ & $\mathrm{C}_{9} \mathrm{H}_{20}$ & & Alkane \\
\hline Decane $^{b}$ & $\mathrm{C}_{10} \mathrm{H}_{22}$ & & Alkane \\
\hline Ethyl hexadecanoate ${ }^{b}$ & $\mathrm{C}_{18} \mathrm{H}_{36} \mathrm{O}_{2}$ & & Ester \\
\hline
\end{tabular}

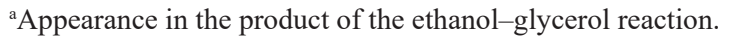

${ }^{\mathrm{b} A p p e a r a n c e}$ in the biofuel sample.

al., 2009; Anitescu et al., 2008; Aimaretti et al., 2009). Aimaretti et al. (2009) reported that approximately $10 \%$ of glycerol reaction products has a marginal influence on the kinematic viscosity. However, the compatibility of those compounds with diesel fuels, and their influence on engine performance, should be investigated in further research.

In the past decade, the prices of glycerol have plummeted because of the rapid increase in global biodiesel production, especially conventional acid and base catalysis processes (Rahmat et al., 2010). Therefore, the purification of crude glycerol to prepare a commercial product, which is a mixture of glycerol, remaining catalyst, soap, unreacted alcohol, and unreacted triglycerides, does not occur to be economically feasible. Although some alternative uses for glycerol have been suggested, the oversupply has led to an environmental problem (Gholami et al., 2014). 
Accordingly, this novel process with SCA at $400{ }^{\circ} \mathrm{C}$ can be considered an environmentally friendly process because of the reduced release of glycerol.

\section{CONCLUSION}

Biofuel production from UPO with SCE with a low ethanol to oil molar ratio was successfully investigated at $400{ }^{\circ} \mathrm{C}$. The high temperature and long reaction time resulted in degradation of unsaturated fatty acids, resulting in a reduction in the total FAEE levels. The optimal reaction conditions were an ethanol to oil molar ratio of $12: 1$ and a reaction time of $10 \mathrm{~min}$. Under these conditions, almost 99\% triglycerides conversion was attained. In addition, the levels of glycerides (mono-, di-, and tri-glycerides) were observed to be within the maximum limits set by the European Standard (EN 14214) for biodiesel fuel. The 50\% distillation recovery was within the range of EN ISO 3405, whereas the $90 \%$ distillation recovery was slightly outside of that range. The side reaction between glycerol and SCE was also examined in this study. The reaction products from glycerol, mostly 2-ethoxy-1,3-propanediol, can positively contribute to improve the cold flow properties and increase the fuel yield by approximately $8 \%$.

\section{ACKNOWLEDGMENTS}

The authors acknowledge the financial support and scholarship from the Thailand Research Fund (IRG5780001), Chulalongkorn University and Faculty of Science of Chulalongkorn University and the Thai Government Stimulus Package 2 (TKK2555), under the Project for Establishment of Comprehensive Center for Innovative Food, Health Products and Agriculture.

\section{REFERENCES}

Abdala, A. C. d. A., Colonelli, T. A. d. S., Trentini, C. P., Oliveira, J. V., Cardozo-Filho, L., Silva, E. A. d. and Silva, C. d. Effect of Additives in the Reaction Medium on Noncatalytic Ester Production from Used Frying Oil with Supercritical Ethanol. Energy \& Fuels, 28, 3122-3128 (2014).

Aimaretti, N., Manuale, D., Mazzieri, V., Vera, C. and Yori, J. Batch study of glycerol decomposition in one-stage supercritical production of biodiesel. Energy \& Fuels, 23, 1076-1080 (2009).

Anitescu, G., Deshpande, A. and Tavlarides, L. L. Integrated Technology for Supercritical Biodiesel Production and Power Cogeneration. Energy \& Fuels, 22, 1391-1399 (2008).

Balat, M. and Balat, H. Progress in biodiesel processing. Applied Energy, 87, 1815-1835 (2010).

Bastida, S. and Sanchez-Muniz, F. J. Polar content vs. TAG oligomer content in the frying-life assessment of monounsaturated and polyunsaturated oils used in deepfrying. Journal of the American Oil Chemists Society, 79, 447-451 (2002).
Carraretto, C., Macor, A., Mirandola, A., Stoppato, A. and Tonon, S. Biodiesel as alternative fuel: Experimental analysis and energetic evaluations. Energy, 29, 2195-2211 (2004).

Cetinkaya, M., Ulusoy, Y., Tekin, Y. and Karaosmanoglu, F. Engine and winter road test performances of used cooking oil originated biodiesel. Energy Conversion and Management, 46, 1279-1291 (2005).

Dias, A. N., Kurz, M. H. S., Fagundes, C. A. M., Caldas, S. S., Clementin, R. M., D’Oca, M. G. M. and Primel, E. G. Evaluation of ASTM D6584 method for biodiesel ethyl esters from sunflower oil and soybean/tallow mixture and for biodiesel methyl esters from tung oil and soybean/tung mixture. Journal of the Brazilian Chemical Society, 25, 11611165 (2014).

Diya'uddeen, B. H., Abdul Aziz, A. R., Daud, W. M. A. W. and Chakrabarti, M. H. Performance evaluation of biodiesel from used domestic waste oils: A review. Process Safety and Environmental Protection, 90, 164-179 (2012).

Encinar, J. M., Sanchez, N., Martinez, G. and Garcia, L. Study of biodiesel production from animal fats with high free fatty acid content. Bioresource Technology, 102, 10907-10914 (2011).

Gholami, Z., Abdullah, A. Z. and Lee, K. T. Dealing with the surplus of glycerol production from biodiesel industry through catalytic upgrading to polyglycerols and other valueadded products. Renewable \& Sustainable Energy Reviews, 39, 327-341 (2014).

Gonzalez, S. L., Sychoski, M. M., Navarro-Díaz, H. J., Callejas, N., Saibene, M., Vieitez, I., Jachmanián, I., da Silva, C., Hense, H. and Oliveira, J. V. Continuous Catalyst-Free Production of Biodiesel through Transesterification of Soybean Fried Oil in Supercritical Methanol and Ethanol. Energy \& Fuels, 27, 5253-5259 (2013).

Hamze, H., Akia, M. and Yazdani, F. Optimization of biodiesel production from the waste cooking oil using response surface methodology. Process Safety and Environmental Protection, 94, 1-10 (2015).

He, H., Sun, S., Wang, T. and Zhu, S. Transesterification Kinetics of Soybean Oil for Production of Biodiesel in Supercritical Methanol. Journal of the American Oil Chemists' Society, 84, 399-404 (2007).

Imahara, H., Minami, E., Hari, S. and Saka, S. Thermal stability of biodiesel in supercritical methanol. Fuel, 87, 1-6 (2008).

Kiwjaroun, C., Tubtimdee, C. and Piumsomboon, P. LCA studies comparing biodiesel synthesized by conventional and supercritical methanol methods. Journal of Cleaner Production, 17, 143-153 (2009).

Knothe, G. "Designer" biodiesel: Optimizing fatty ester (composition to improve fuel properties. Energy \& Fuels, 22, 1358-1364 (2008).

Kusdiana, D. and Saka, S. Effects of water on biodiesel fuel production by supercritical methanol treatment. Bioresource technology, 91, 289-295 (2004).

Lee, K. T. and Ofori-Boateng, C. Sustainability of biofuel production from oil palm biomass. Springer (2013).

Ma, F. and Hanna, M. A. Biodiesel production: a review. Bioresource Technology, 70, 1-15 (1999). 
Marulanda, V. F., Anitescu, G. and Tavlarides, L. L. Biodiesel fuels through a continuous flow process of chicken fat supercritical transesterification. Energy \& Fuels, 24, 253-260 (2009).

Marulanda, V. F., Anitescu, G. and Tavlarides, L. L. Investigations on supercritical transesterification of chicken fat for biodiesel production from low-cost lipid feedstocks. Journal of Supercritical Fluids, 54, 53-60 (2010).

Math, M. C., Kumar, S. P. and Chetty, S. V. Technologies for biodiesel production from used cooking oil - A review. Energy for Sustainable Development, 14, 339-345 (2010).

Minami, E. and Saka, S. Kinetics of hydrolysis and methyl esterification for biodiesel production in two-step supercritical methanol process. Fuel, 85, 2479-2483 (2006).

Rahmat, N., Abdullah, A. Z. and Mohamed, A. R. Recent progress on innovative and potential technologies for glycerol transformation into fuel additives: A critical review. Renewable and Sustainable Energy Reviews, 14, 987-1000 (2010).

Rodrigues, S., Mazzone, L. C. A., Santos, F. F. P., Cruz, M. G. A. and Fernandes, F. A. N. Optimization of the production of ethyl esters by ultrasound assisted reaction of soybean oil and ethanol. Brazilian Journal of Chemical Engineering, 26, 361-366 (2009).

Sakdasri, W., Sawangkeaw, R. and Ngamprasertsith, S. Continuous production of biofuel from refined and used palm olein oil with supercritical methanol at a low molar ratio. Energy Conversion and Management, 103, 934-942 (2015).

Sawangkeaw, R., Teeravitud, S., Bunyakiat, K. and Ngamprasertsith, S. Biofuel production from palm oil with supercritical alcohols: effects of the alcohol to oil molar ratios on the biofuel chemical composition and properties. Bioresource technology, 102, 10704-10710 (2011).
Sawangkeaw, R., Teeravitud, S., Piumsomboon, P. and Ngamprasertsith, S. Biofuel production from crude palm oil with supercritical alcohols: comparative LCA studies. Bioresour Technol, 120, 6-12 (2012).

Silva, C., Colonelli, T. A. S., Silva, E. A., Cabral, V. F., Oliveira, J. V. and Cardozo-Filho, L. Continuous catalyst-free production of esters from Jatropha curcas L. oil under supercritical ethanol. Brazilian Journal of Chemical Engineering, 31, 727735 (2014).

Silva, C. d. and Oliveira, J. V. Biodiesel production through noncatalytic supercritical transesterification: current state and perspectives. Brazilian Journal of Chemical Engineering, 31, 271-285 (2014).

Song, E. S., Lim, J. W., Lee, H. S. and Lee, Y. W. Transesterification of RBD palm oil using supercritical methanol. Journal of Supercritical Fluids, 44, 356-363 (2008).

Tan, K. T., Lee, K. T. and Mohamed, A. R. Effects of free fatty acids, water content and co-solvent on biodiesel production by supercritical methanol reaction. Journal of Supercritical Fluids, 53, 88-91 (2010).

Varma, M. N. and Madras, G. Synthesis of Biodiesel from Castor Oil and Linseed Oil in Supercritical Fluids. Industrial \& Engineering Chemistry Research, 46, 1-6 (2007).

Vieitez, I., da Silva, C., Alckmin, I., de Castilhos, F., Oliveira, J. V., Grompone, M. A. and Jachmanián, I. Stability of ethyl esters from soybean oil exposed to high temperatures in supercritical ethanol. The Journal of Supercritical Fluids, 56, 265-270 (2011).

Vieitez, I., Irigaray, B., Casullo, P., Pardo, M. J., Grompone, M. A. and Jachmanian, I. Effect of Free Fatty Acids on the Efficiency of the Supercritical Ethanolysis of Vegetable Oils from Different Origins. Energy \& Fuels, 26, 1946-1951 (2012). 